\title{
The impact of depression on driver performance
}

\author{
Wickens, C. M., Smart, R. G., \& Mann, R. E.
}

Version Post-Print/Accepted Manuscript

Citation Wickens, C. M., Smart, R. G., \& Mann, R. E. (2014). The impact of (published version) depression on driver performance. International Journal of Mental Health and Addiction, 12, 524-537.

Publisher's Statement The final publication is available at Springer via http://dx.doi.org/10.1007/s11469-014-9487-0.

Always cite the published version, so the author(s) will receive recognition through services that track citation counts, e.g. Scopus. If you need to cite the page number of the TSpace version (original manuscript or accepted manuscript) because you cannot access the published version, then cite the TSpace version in addition to the published version using the permanent URI (handle) found on the record page. 
Running head: THE IMPACT OF DEPRESSION ON DRIVER PERFORMANCE

\title{
The Impact of Depression on Driver Performance
}

\author{
Christine M. Wickens ${ }^{1}$, Reginald G. Smart ${ }^{1}$, Robert E. Mann ${ }^{1,2}$ \\ ${ }^{1}$ Social and Epidemiological Research Department, Centre for Addiction and Mental Health, \\ Toronto, Ontario, Canada \\ ${ }^{2}$ Dalla Lana School of Public Health, University of Toronto, Toronto, Ontario, Canada
}

Correspondence concerning this article should be addressed to:

Dr. Christine M. Wickens

Centre for Addiction and Mental Health

Social and Epidemiological Research Department

33 Russell Street, T417

Toronto, Ontario M5S 2S1

Canada

Email: Christine.Wickens@camh.ca

Telephone: (416) 535-8501 ext. 4711

Fax: (416) 595-6899 


\begin{abstract}
This study reviews the existing literature concerning the association between depression and driver safety. Despite its increasing prevalence and its disabling impact on the world's population, there is surprisingly little research examining the impact of depressive disorders on driver performance. The review begins by examining the early studies of drivers deemed "mentally ill" and the subsequent epidemiological literature including case-control and prospective cohort studies of depressed drivers. The review also examines the more recent experimental investigations of depression and driver performance that have relied on naturalistic measurements and advanced driving simulation. The review concludes with a discussion of relevant issues (e.g., the impact of antidepressants on driver performance, suicide by driving), public policy implications of the research, and future research directions.
\end{abstract}

Keywords: Depression, mental health, driving, collisions, aggression 
The Impact of Depression on Driver Performance

Motor vehicle collisions (MVCs) are a leading cause of disability and premature mortality worldwide (World Health Organization 2009). Many factors have been identified as having a potentially contributory impact on MVC-risk and unsafe driver behaviours; however, driver safety researchers have not empirically assessed each of these variables. One of the potential contributors to MVC-risk which has received only limited empirical attention is mental health. Several psychological disorders have been identified as potentially detrimental to driver performance (Wickens et al. 2014), with some receiving more research attention than others.

Depression is a form of mood disorder characterized by feelings of sadness, hopelessness, or misery and a loss of interest or pleasure in nearly all activities. It can be associated with suicidal thoughts or self blame, and can interfere with an individual's ability to perform routine daily functions (Charlton et al. 2004). The prevalence of depression-related disorders in North American countries was estimated to be approximately 10.9 million in 2000 , approximately $3 \%$ of the total population (Charlton et al. 2004). Age-related differences have been identified, with older adults reporting higher prevalence rates for the disorder (Marshall 2008). According to some estimates, depression is the leading cause of disability in the world (NIMH 2007, as cited in Osterman et al. 2009), and rates of depression are expected to rise significantly over the next two decades in response to our ageing population, increasing poverty, and rapid global transformations (Charlton et al. 2004).

An increasing body of research confirms that individuals experiencing depression are at risk for premature mortality (Wulsin et al. 1999; Wyman et al. 2012). Contrary to common expectation, excess mortality risk associated with depression is not explained by suicide (e.g., Mykletun et al. 2007; Wyman et al. 2012). According to Hernetkoski et al. (2009), on-the-road 
suicides account for only $2 \%$ of all suicides but a larger percentage of total road fatalities. Estimates go as high as $15 \%$ but the most frequent estimates range from approximately 8 to $9 \%$ (Isherwood et al. 1982; Keskinen and Pasanen 1990; Kuroda and Pounder 1994). It has been suggested that depression may affect driving skills and behaviours (e.g., Selzer and Vinokur 1975; Wingen et al. 2006); however, there is surprisingly little research examining the impact of depression on driver performance and collision risk (Dobbs 2005; Hollister 1992). Most previous reviews of this literature are restricted to the 'grey literature', have been based on a relatively small number of studies, and have been inconclusive (Charlton et al. 2004; Dobbs 2005; Marshall 2008; Vaa 2003).

Since depression is among the most common psychiatric disorders affecting the population, an impact on driver performance and collision risk could have substantial implications in several areas, including quality of life considerations for those with the disorder, and for traffic safety. Thus, the current paper will outline in detail the present state of knowledge on the issue. Through a narrative review, the paper will first discuss the early driving safety studies which examined mental health generally, and will subsequently outline the epidemiological and experimental research of the driving-related effects of depression, specifically. The review will conclude by identifying related issues and future directions for research. It should be noted that the impact of depression on driving behaviour impaired by alcohol and drugs will not be addressed in the current review. This relationship has been well established in the literature, and there is insufficient space to allow for a thorough review of this issue. 


\section{Studies of Persons Deemed Mentally III}

Persons with mental illness, especially in the acute untreated phase, are likely to have diminished cognitive abilities, inability to concentrate, and slowed reaction time. These are all functions that are necessary in driving a road vehicle safely. Approximately $80 \%$ of depressive in-patients hold a valid drivers' licence, and approximately $70 \%$ of these patients drive regularly (Brunnauer and Laux 2013). Several medical guidelines suggest that patients should not drive when their psychiatric problems are acute (Canadian Medical Association 2006; Carter 2006; NZ Transport Agency 2009).

A few early studies have examined rates of road accidents and violations in drivers with "mental illness". Other studies have looked at the performance of the mentally ill on driver simulators. These studies include a catch-all category (e.g., "mental illness" or "psychiatric disorders") and typically contain little or no analysis by type of disorder.

The first study of mental illness and driving risk was done by Waller (1965). It was based on the driving records of 2,672 drivers in California whose licenses were under medical review. Supposedly this review was occurring because of some increased risk due to their illness. In this study 292 drivers were diagnosed with a "mental illness". These drivers had reported accident rates of 15.3 per million miles driven compared to 7.2 per million in the general population. They also had a higher rate of driver violations. Miles driven were estimated and could be somewhat in error. Waller's study had several other limitations. It did not sample mentally ill drivers in general, only those who came to the attention of licensing agencies. It may therefore have overestimated the rate of accidents and violations among mentally ill drivers in general. Also no data were provided for separate sub-categories of the mentally ill sample (e.g., depression, anxiety, schizophrenia, etc.). 
Another study by Buttiglieri and colleagues involved several statistical analyses published over a span of several years. The research examined the driving records of 361 psychiatric in-patients for the 3-year period preceding hospitalization. The earliest analyses reported no difference in collision and driving violation records between the psychiatric inpatients and a random sample of male California drivers (Buttiglieri and Guennette 1967a,b), although a small but significant group (3\%) of the in-patients had driving records that identified them as "negligent operators" (Buttiglieri and Guennette 1967a). Subsequent analyses contrasting a larger psychiatric in-patient sample $(n=533)$ with the general population group replicated the lack of a significant finding concerning the rate of collision involvement; however, a significantly greater number of driving violations was found for the in-patient psychiatric sample (Buttiglieri et al. 1969). Unfortunately, this study did not measure driving exposure. In response to this limitation, the authors applied exposure estimates from Waller's study (1965), and found no change in the relationship. Still, there is no way to confirm that the exposure data from Waller's study were even remotely accurate estimates of exposure for the sample used in Buttiglieri et al.'s studies.

A small study by Cushman et al. (1990) provided results consistent with Buttiglieri and Guennette's (1967a,b) earlier findings. Cushman et al. studied a group of 1,775 accident victims seen in ten hospitals in New York State. Drivers having a current or past psychiatric diagnosis did not have more single vehicle accidents or road violations than controls without psychiatric diagnosis. However, the study included only single vehicle accidents, and no analyses were made for particular diagnostic groups. Also, the comparison of drivers with a psychiatric disorder was based only on 17 cases with 17 controls. Lastly, the data were drawn from collisions where 
someone was injured sufficiently to need hospital care, which means that most collisions were excluded from analyses.

Bech (1975) examined the driving abilities of 46 psychiatric in-patients using a rudimentary driving simulator, which consisted of a cyclorama with painted landscape that rotated in response to the operator's depression of an accelerator pedal. Based on the presence of psychotic symptoms, participants were divided into psychotic and non-psychotic groups, although a variety of diagnostic categories were represented in each group. Participants were also matched for age, sex, and driving experience. Results of the study found no differences in speed or number of gear changes; however, psychotic patients had a significantly prolonged brake response time, particularly toward the end of the driving period indicating poor vigilance. This difference between groups disappeared once anti-psychotic drug treatment had been initiated. Unfortunately, this study did not include a control group of drivers without mental illness, and the restricted number of participants in the study suggests cautious interpretation of the results.

Fortunately, more recent studies have involved larger samples. De Las Cuevas and Sanz (2008) used a driving simulator to assess driving fitness among 208 consecutive psychiatric outpatients in the Canary Islands. No analyses were made for psychiatric sub-categories. The study assessed attention, reaction time, anticipation of speed, coordination, decision-making skills, and risk-taking. Of the 208 patients, $84 \%$ failed at least one of the tests and $79.5 \%$ had scored too low to get a license renewal. A later study (De Las Cuevas and Sanz 2009) found that of 120 psychiatric patients who drove regularly and had a license, only 24 passed the simulator tests necessary to get a license. In another study, De Las Cuevas et al. (2010) examined psychiatric out-patients at two time points. When destabilized patients were examined at admission, only $10 \%$ could do the simulator tests necessary to drive safely. However, when tested after 6 weeks 
of "appropriate" psychotropic treatment, $25 \%$ could do the test well enough to drive safely. No comparisons were made with drivers who did not have psychiatric problems.

Only one case-control study has been found examining road death in relation to psychiatric problems in general. Dumais et al. (2005) compared 61 young Canadian males who died in a MVC with a similar group of living male drivers. Drivers under age 25 years were found to be comparable in "all measures of psychopathology" when psychological autopsies were done. In drivers aged 26 years or older, only cluster B personality disorders (borderline and antisocial) were associated with more MVCs. Depression was not seen as more prominent among MVC-involved drivers.

Most but not all studies of people with undifferentiated mental illness or psychiatric problems show that these drivers do not have higher collision or fatality rates, but they do demonstrate more violations and perform more poorly on driving simulators. However, most of these studies have been flawed. Clear comparisons with drivers not having psychiatric problems have often not been made. Differences in driving exposure have not always been considered. Most importantly, the significant variation in the impact of different psychiatric diagnoses should be considered when examining the relationship between mental illness and driver performance. For these reasons, based on studies of unspecified mental illness, a clear conclusion concerning the relationship between psychiatric disorder and driver performance is difficult to make and a conclusion concerning the relationship between depression specifically and driver performance is not possible. 


\section{Epidemiological Studies of Depressed Drivers}

Studies that have focused on depressed drivers specifically as opposed to the "mentally ill" have generally adopted epidemiological case-control or prospective cohort designs. These studies have examined the impact of depression on two primary outcome measures: (a) MVCrisk or the probability of being at-fault for a MVC, and (b) the incidence of aggressive or risky driving.

\section{Increased Collision Risk}

There have been several case-control studies focused on the impact of depression on MVC-risk. The results of these studies have been mixed; however, the majority has identified depression as a contributor to increased collision risk. Selzer et al. (1968) compared 96 drivers deemed responsible for fatal MVCs with 96 control drivers matched for age, sex, and home county. Interviews with surviving drivers and their families and reviews of arrest and traffic records revealed that the rates of paranoid ideation, suicidal proclivity, and clinical depression were greater among the MVC-involved drivers (41\% reported at least one symptom of psychopathology) than the control drivers (17\% reported at least one symptom). Moreover, these drivers experienced significantly more personal conflict and vocational-financial stress than control drivers, and they experienced acutely disturbing events such as quarrels with others within $6 \mathrm{~h}$ of causing the fatal MVC. Fifty-two percent of MVC-involved drivers had experienced stress versus just $18 \%$ of control drivers. Likewise, Selzer and Vinokur (1975) surveyed male drivers from Michigan above the age of 20 years, including 102 drivers recruited from a local drivers' licensing office and 135 drivers recruited from a traffic school which they were ordered to attend following a conviction for moving traffic violations. Although the results only approached significance, it was found that depression $(p=0.07)$ and various measures of life 
events stress ( $p=0.02$ to 0.17 ) were greater among those drivers who had been involved in a MVC compared to those who had not.

Holt (1981) surveyed drivers admitted to orthopaedic wards following a MVC. Drivers deemed at-fault for the collision reported experiencing significantly more stressful life events in the year preceding the collision and reported more symptoms of psychological disturbance than did the not-at-fault drivers. In a more advanced study, Sagberg (2006) surveyed Norwegian drivers who had reported a MVC to their insurance company and examined the crash risk posed by various medical conditions. Likelihood of being at-fault for the collision was examined in drivers with and without each medical condition. Sagberg reported an odds ratio of 2.43 for 'feeling depressed', indicating that drivers who reported feeling depressed were more than twice as likely to be at-fault for the collision than drivers who did not report such feelings. It should be noted, however, that the response rate for the survey was only $30 \%$ and that questionnaires were completed several months after the collision, suggesting that feelings of depression may not have been present at the time of the collision. Koepsell and colleagues (1994) conducted a matched case-control study of drivers aged 65 years and older. They found that individuals who had been injured while driving were more likely to have been diagnosed with depression in the 3 years before the MVC than non-injured drivers matched for age, gender, and county of residence $(\mathrm{OR}=1.7)$; however, this effect only approached statistical significance.

In a similar study, Rainio et al. (2007) examined reports of 542 fatal MVCs from road accident investigation teams in Finland. Results revealed that psychiatric diseases, including depression, were diagnosed more often among deceased drivers who had contributed significantly to their MVC than among any other groups of drivers, including surviving drivers who contributed significantly to their MVC and deceased passengers. In a survey of Australian 
heavy goods vehicle drivers, Hilton et al. (2009) identified a relationship between symptoms of depression and driver performance. Specifically, severe and extremely severe depression symptoms were associated with more than a four-fold increase in the risk of a MVC $(\mathrm{OR}=4.4)$ and a five-fold increase in the risk of a near-miss $(\mathrm{OR}=5.0)$.

Finally, in separate analyses of a general population survey of adults in Ontario, Canada, researchers examined the impact of psychological distress on collision involvement. In the first analysis, Mann et al. (2010) reported that increased scores on a measure of depression-anxiety were associated with an increased risk of collision $(\mathrm{OR}=1.05)$. In a subsequent analysis, Wickens et al. (2013) used a new scoring method for the same measure, that had since been validated as a suitable proxy measure of anxiety and mood disorder (AMD) for epidemiological and surveillance purposes (Mann et al. 2011). This analysis demonstrated an even stronger association, with the presence of AMD nearly doubling the risk of a MVC $(\mathrm{OR}=1.78)$.

Although the majority of case-control studies appear to have identified an increased risk of MVC-involvement among those with symptoms of depression, not all case-control studies have done so. Isherwood et al. (1982) compared 150 suicide attempters and 100 drivers involved in MVCs with 200 controls drawn randomly from the general population. Although depression was the most important factor associated with a suicide attempt, depression did not differ between controls and MVC-involved drivers. In another study, Vingilis and Wilk (2007) examined longitudinal data from the Canadian National Population Health Survey for the years 1994-2002. Respondents who reported experiencing psychological distress reported a higher percentage of subsequent MVC injuries; however, distress was not a significant predictor of MVC injury risk when other factors such as binge drinking, health status, and medication use were considered simultaneously in the analysis. A subsequent analysis by Vingilis and Wilk 
(2012) again examined psychological distress, along with the impact of antidepressant use on MVC injuries. In the latter analysis, psychological distress was not associated with increased risk of MVC injury, although greater injury was found to be related to antidepressant use independent of the level of distress.

Many of the prospective cohort studies examining the relationship between depression and collision risk have focused on older drivers and, like the case-control studies, have also produced mixed results. Sims and colleagues (2000) followed a group of 174 older adults from 1991 through 1996. Drivers reporting symptoms of geriatric depression in 1991 were 2.5 times more likely to be involved in a MVC in the following five years. Likewise, Cross et al. (2009) pooled data from four cohorts of older drivers and found that depression was associated with an increased risk of MVC involvement, although the effect only approached statistical significance. On the contrary, Marottoli and colleagues (1994) examined a probability sample of 283 noninstitutionalized persons aged 72 years and older living in New Haven, Connecticut. Depressive symptoms assessed by the Center for Epidemiologic Studies-Depression scale had no impact on the number of times drivers were stopped by police, committed moving violations, or were involved in a MVC. Likewise, Margolis et al. (2002) examined data from 1,416 older women enrolled in the Study of Osteoporotic Fractures. Again, depression was not a significant predictor of MVC involvement; however, only 3.5\% of this sample scored high on the measure of geriatric depression, suggesting that the study may have lacked the necessary power to identify an association. Finally, rather than assessing older drivers, Martiniuk et al. (2010) examined data from novice Australian drivers aged 17-24 years. Compared to the referent group of novice drivers reporting no or low psychological distress, those drivers reporting moderate 
distress experienced a reduced risk of MVC involvement $(\mathrm{RR}=0.87)$. No effect was found for drivers reporting severe psychological distress.

Epidemiological research examining the relationship between depression and collision risk has been affected by several generally consistent limitations. Both case-control studies and prospective cohort studies have often been limited by failure to control for driving exposure or mileage (e.g., Selzer et al. 1968; Selzer and Vinokur 1975), low response rates or sample sizes (e.g., Hilton et al. 2009; Sagberg 2006; Sims et al. 2000), neglecting less serious collisions (e.g., Koepsell et al. 1994; Vingilis and Wilk 2007, 2012; Margolis et al. 2002; Marottoli et al. 1994), possible underreporting of both collisions and psychiatric conditions due to reliance on selfreport (e.g., Cross et al. 2009; Mann et al. 2010; Sagberg 2006; Wickens et al. 2013), and the use of numerous statistical tests that may have resulted in some associations occurring by chance alone (e.g., Koepsell et al. 1994; Sims et al. 2000). Perhaps due in part to these limitations, the results of these studies have been inconsistent; however, there does appear to be some evidence that depression is associated with increased collision risk.

\section{Aggressive and Risky Driving}

Aggressive and risky driving behaviour contributes to a significant number of deaths and injuries on the roadways (AAA Foundation for Traffic Safety 2009; Road rage: Causes et al. 1997). Studies examining the relationship between depression and aggressive or risky driving behaviour have been much more consistent than those examining depression and MVC-risk, predominantly demonstrating a positive association. Several case-control studies have found such an effect. Fong et al. (2001) recruited patients from a general practitioner's office to participate in a survey study. Based on their survey responses, patients were assigned to a road rage perpetrator group, victim group, perpetration and victim group, or a control group. 
Compared to control patients, both perpetrators and victims demonstrated greater psychiatric morbidity. The authors suggested that these symptoms may have made perpetrators more susceptible to roadway provocation and victims more vulnerable to driving behaviours or errors that might provoke another driver. They concluded that lower levels of psychological/psychiatric distress may, therefore, protect from involvement in incidents of roadway aggression.

A general population survey of adults in Ontario, Canada reported similar findings (Butters et al. 2006). Three separate logistic regression analyses were conducted to predict road rage victimization, road rage perpetration, and involvement with serious road rage behaviour (defined as victimization by or perpetration of the most serious road rage incidents including attempting to damage another's car or to hurt other roadway users). Results indicated that the presence of psychiatric distress significantly increased the odds of road rage victimization and serious road rage involvement; however, it did not impact the risk of road rage perpetration.

In another study, Yu et al. (2004) recruited a sample of 431 clients attending an alcoholism and substance abuse treatment program following a drink-driving conviction. Survey results from the sample indicated that, depending on the model specified, depression was often predictive of risky driving which included behaviours such as speeding, running amber lights, and running stop signs. Regardless of the model specified, depression was always predictive of road rage which included behaviours such as tailgating, cutting off others, yelling, gesturing, and honking.

Finally, based on data from the National Epidemiologic Survey on Alcohol and Related Conditions (NESARC), collected through face-to-face structured psychiatric interviews, Vaughn et al. (2011) reported that a diagnosis of major depression was associated with reckless driving. Specifically, respondents were asked three questions: In your entire life, (a) "did you ever do 
things that could easily hurt you or someone else like speeding or driving after too much to drink?”; (b)“did you ever get more than three tickets for reckless/careless driving, speeding, or causing an accident?"; and (c) "did you ever have a driver's license suspended or revoked for moving violations?" Respondents who answered 'yes' to just the first question were identified as episodic reckless drivers. A diagnosis of major depression was associated with an increased risk of episodic reckless driving (adjusted OR=1.16). Respondents who answered 'yes' to the second question were identified as chronically reckless, and again major depression was associated with an increased risk of chronic reckless driving (adjusted $\mathrm{OR}=1.21$ ). Respondents who responded 'yes' to the third question were identified as chronic and severe reckless drivers; however, no association was found between this category and depression.

There are very few studies that suggest a lack of relationship between depression and aggressive or risky driving behaviour. One of the few such studies was a longitudinal cohort study following 1,055 young Australian drivers over a 23-year period (Vassallo et al. 2008). Depression measured throughout the teen years was generally unrelated to risky driving which included behaviours such as speeding, not wearing a seatbelt, driving when tired, driving after drinking, and driving under the influence of drugs.

Beyond the case-control and cohort studies, there is a series of other correlational research that also lends credence to the hypothesized relationship between depression and aggressive or risky driving. For instance, Deery and Fildes (1999) conducted a cluster analysis on various self-reported personality and driving-related measures completed by 198 novice drivers aged 16 to 19 years. A five-cluster solution was produced. One of the two most high-risk clusters was characterized by high levels of driving aggression, competitive speed, driving to reduce tension, sensation seeking, assaultiveness, and hostility. This group was also 
characterized by low levels of emotional adjustment and high levels of depression. Likewise, in an online survey of novice drivers aged 17 to 25 years in Queensland, Australia, regression analyses revealed that psychological distress uniquely explained $8.5 \%$ of the variance in young novices' risky driving behaviour (Scott-Parker et al. 2011). For both male and female novice drivers, those who reported psychological distress also reported higher levels of risky driving.

Finally, a program of research conducted by Galovski et al. (2006) has contrasted treatment-seeking aggressive drivers to a community control sample of non-aggressive drivers. Results from this research program have been extremely mixed. In exploratory assessments of their samples, Galovski et al. found a non-significant trend $(p=0.071)$ for aggressive drivers to be more likely to meet criteria for current mood disorders than the control participants. However, there were no differences between the groups in terms of past mood disorder. Moreover, there was a higher likelihood of a current mood disorder among aggressive drivers with Intermittent Explosive Disorder (IED) than among aggressive drivers without this diagnosis; however, there was no difference in psychiatric distress among IED-positive and IED-negative aggressive drivers. In a related study, when comparing a university sample of high- and low-aggressive drivers, no significant differences in current or lifetime prevalence of mood disorders were found (Malta et al. 2005). Given the incongruous results from the various studies included in this research program, it is difficult to draw any firm conclusions from it.

As with the epidemiological studies of the relationship between depression and collision risk, the studies of the relationship between depression and aggressive driving behaviour also suffer from many of the same relatively consistent limitations. The vast majority of studies relied on self-report which may have resulted in the underestimation of socially undesirable behaviours such as driver aggression. Several studies faced problems of low response rate or sample size and 
attrition, which may have impacted statistical power and generalizability (e.g., Fong et al. 2001; Vassallo et al. 2008). Still, the majority of epidemiological research examining the issue has provided evidence to suggest that depression contributes to driver aggression.

\section{What Epidemiological Research Has Yet To Tell Us}

Overall, although the results have certainly been mixed, it appears that there is some epidemiological evidence that depression may have a detrimental impact on collision risk. Additional research is needed to more fully understand the factors that might mediate or moderate this effect, and which might explain the inconsistency in findings. Age and the severity of depression are both potential candidates. Likewise, overall, there also appears to be epidemiological evidence that depression is associated with increased aggressive and risky driving behaviour. Neuroscientists have suggested that this correlation between depression and aggression may result from a common etiology; namely the dysfunctional transmission of serotonin (Bjork et al. 1997; Carver et al. 2008). Still, what remains to be understood is precisely how depression impacts driver performance. Although the increased aggression evidenced in depressed drivers may explain some of their increased MVC-risk, are there other ways in which depression may impact driver performance, and hence driver safety? Experimental paradigms have provided a few answers to this research question.

\section{Experimental Studies of Depressed Drivers}

Many experimental studies have assessed the impact of depression on cognitive and psychomotor functioning thought to be related to driver performance (e.g., Hammar et al. 2003; Sabbe et al. 1999). Yet the assumed relationship between cognitive/psychomotor functioning and driver behaviour is not consistently demonstrated by empirical investigation (e.g., Verster and Roth 2012). More ecologically valid experimental research has utilized actual on-road driver 
performance or advanced driving simulation technology, which has been demonstrated to be predictive of on-road driver behaviour (de Winter et al. 2009); however, few such studies have been conducted.

As described previously, Deery and Fildes (1999) conducted a cluster analysis of personality and driving-related measures completed by 198 young novice drivers which identified five subtypes of drivers. One of these clusters included drivers who demonstrated strong roadway aggression, competitive speeding, and hostility, and who demonstrated higher levels of depression. In a second study, Deery and Fildes asked drivers from each of the five identified subtypes to complete a driving simulation task. The subtypes differed in terms of several behavioural responses. Drivers who had been identified as highly aggressive but also depressed demonstrated difficulty in anticipating potentially hazardous events. They also demonstrated difficulty in controlling their attention between competing tasks in a driving situation and a lack of caution in terms of driving speed in an emergency situation.

A quasi-experimental simulation study of depression and driver performance was conducted by Bulmash and colleagues (2006) who compared the driving simulator performance of 18 out-patients diagnosed with Major Depressive Disorder with 29 control participants. After controlling for age and sleepiness, the sample of untreated depressed patients exhibited slower steering reaction times and a greater number of crashes than control participants. In both cases, the differences were characterized as being medium effect sizes. The authors suggested that the slowed reaction time may have been the result of depression-related impairment in allocating cognitive resources among various cognitively complex driving subtasks. This interpretation would be consistent with the finding of Deery and Fildes (1999) that drivers with more 
depressive symptoms demonstrated greater difficulty in dividing attention between competing driving-related tasks.

Brunnauer et al. (2008) randomly assigned 40 depressed in-patients to receive treatment with either reboxetine or mirtazapine. Their simulated driving ability was assessed before and after initiation of the treatment medication. Compared to a group of ten healthy control participants, prior to receiving their medication depressed in-patients were involved in a significantly greater number of simulated collisions. Cognitive and psychomotor testing also revealed that untreated in-patients performed more poorly than healthy controls in their selective attention and reactivity/stress tolerance.

Wingen et al. (2006) experimentally assessed actual driving performance of 24 depressed patients receiving selective serotonin reuptake inhibitor (SSRI) or serotonin and noradrenalin reuptake inhibitor (SNRI) treatment for 6-52 weeks. The depressed patients' driving performance was compared to healthy controls matched for age, gender, and years of driving experience. Results of the study indicated that medicated patients demonstrated a greater weaving motion in their driving, as well as impairment of their ability to adapt to the changing speed of a leading vehicle. In cognitive testing, depressed patients also demonstrated impairment of their critical flicker fusion threshold, indicating reduced arousal and activation of the central nervous system. This may indicate that the impaired driving performance of depressed patients was due to reduced energetic resources or central arousal, which is consistent with reports of poorer sleep quality among patients versus controls. Based on evidence that SSRIs generally do not affect weaving in healthy drivers, the authors concluded that the driving impairment demonstrated by the depressed patients was most likely caused by the residual depression itself, as opposed to any side effects of their treatment medication. 


\section{What Experimental Research Has Yet To Tell Us}

Although only a limited amount of experimental research has been conducted, results suggest that the performance of depressed drivers may be impaired. These motorists experience difficulty with reaction time, divided attention, reacting to changing speeds when following another vehicle, and weaving more within lane, all of which may result in an increased risk of collision. Much more experimental research is needed to fully comprehend the impact of depression on driver behaviour and its implications for collision risk.

It is also imperative that future investigations do not confound the effects of depression with the effects of its treatment medications. Wingen at al. (2006) contrasted healthy control participants with medicated depressed drivers, instead of assessing unmedicated depressed drivers. This design flaw made it impossible to determine if the behavioural driving-related effects demonstrated in the study were the result of psychopathology or antidepressant medication. This latter possibility is, in itself, another important research question: does antidepressant medication improve or hinder the performance of depressed drivers? While there is a dearth of knowledge on the topic (see Brunnauer and Laux (2013); Linnoila and Seppala (1985) for a review of the available literature), it is likely that the impact of antidepressant medications may be determined mainly by their sedative effect profile (Dassanayake et al. 2011; Ramaekers 2003). Although a full discussion of the impact of antidepressant medications on driver performance is beyond the scope of the current review, it should be noted that most of the experimental studies examining this issue have tested antidepressant medications on healthy volunteers instead of examining their impact on depressed drivers (Brunnauer and Laux 2013). Future experimental research is needed to determine the impact of all types of antidepressant 
medication on depressed drivers specifically, in order to determine if treatment increases or reduces their risk of collision.

\section{Conclusions}

The research to date examining the potential impact of depression on driver performance has produced mixed results. Predominantly early studies examined drivers with any psychiatric diagnosis within a single catch-all category. Results generally indicated that these drivers do not have higher collision or fatality rates, but they do commit more violations and perform more poorly on driving simulators. However, in light of a number of serious methodological limitations associated with studies of unspecified mental illness, a firm conclusion concerning the relationship between depression and driver performance cannot be drawn based on this research. Epidemiological studies focused specifically on drivers experiencing psychological distress or depression have provided more insight. These studies suggest that depressed drivers engage in more risky and aggressive roadway behaviour, and face a greater risk of collision. Only a few experimental studies using on-the-road performance or simulation have focused on the behavioural impact of depression, and these studies indicate that depressed drivers encounter difficulty with reaction time, divided attention, reaction to changing speeds when following another vehicle, and weaving within lane. These difficulties are likely to impact drivers' risk of collision.

Overall, the existing literature suggests that driver safety may be at risk when a diagnosis of depression is present. A significant amount of epidemiological research supports this conclusion, but more experimental research is necessary. Naturalistic and simulation studies should be conducted to identify and confirm the cognitive, emotional, and behavioural impact of depression in the roadway environment. For instance, are depressed drivers more likely to 
attribute potentially offensive roadway behaviours to deliberate intent? Are these drivers more likely to become angry or to respond aggressively? Are they more likely to engage in risky driving behaviour (e.g., driving at a higher speed, passing a slow moving vehicle in the oncoming traffic lane with less time to spare)? Do they perceive hazards in the roadway environment the same way as do other drivers? Experimental research, which can draw causeand-effect conclusions, is necessary to answer these research questions.

The issue of antidepressant medication and its impact on driver performance is highly important. Although it has not been thoroughly outlined in the current review, it is essential to driver safety that the driving-related effects of all types of antidepressant medication are well understood. Some past research has confounded the effects of depression with its treatment medication (e.g., Wingen et al. 2006), and other studies have looked at the impact of antidepressants on healthy drivers (Brunnauer and Laux 2013). The advancement of driver simulation technology presents an excellent opportunity to address this research question and to resolve methodological limitations of previous investigations.

Research addressing all of these issues would greatly inform public policy concerning mandatory reporting laws. In many jurisdictions, healthcare providers including physicians and psychiatrists are required by law to report patients who may be unfit to drive for medical reasons to the appropriate authorities. More specific guidelines are currently lacking, making the decision to report a potentially unfit patient much more difficult. Future investigations will need to achieve a delicate balance between maintaining the safety of depressed drivers and other roadway users and maximizing depressed drivers' mobility and quality of life. 


\section{Acknowledgments}

This research was supported by a grant from AUTO21, a member of the Networks of Centres of Excellence (NCE) program that is administered and funded by the Natural Sciences and Engineering Research Council (NSERC), the Canadian Institutes of Health Research (CIHR), and the Social Sciences and Humanities Research Council (SSHRC), in partnership with Industry Canada. Dr. Wickens was supported by Postdoctoral Fellowships from the SSHRC and the Centre for Addiction and Mental Health. 


\section{Conflict of Interest}

On behalf of all authors, the corresponding author states that there is no conflict of interest. 


\section{References}

AAA Foundation for Traffic Safety. (2009, April). Aggressive driving: Research update. Retrieved from https://www.aaafoundation.org/sites/default/files/AggressiveDrivingResearchUpdate2009 .$p d f$

Bech, P. (1975). Mental illness and simulated driving: Before and during treatment. Pharmakopsychiatrie, Neuro-Psychopharmakologie, 8, 143-150.

Bjork, J. M., Dougherty, D. M., \& Moeller, F. G. (1997). A positive correlation between selfratings of depression and laboratory-measured aggression. Psychiatry Research, 69, 3338. doi: 10.1016/S0165-1781(96)03025-9

Brunnauer, A., \& Laux, G. (2013). The effects of most commonly prescribed second generation antidepressants on driving ability: a systematic review. Journal of Neural Transmission, 120, 225-232. doi: 10.1007/s00702-012-0833-8

Brunnauer, A., Laux, G., David, I., Fric, M., Hermisson, I., \& Möller, H.-J. (2008). The impact of reboxetine and mirtazapine on driving simulator performance and psychomotor function in depressed patients. Journal of Clinical Psychiatry, 69, 1880-1886.

Bulmash, E. L., Moller, H. J., Kayumov, L., Shen, J., Wang, X., \& Shapiro, C. M. (2006). Psychomotor disturbance in depression: Assessment using a driving simulator paradigm. Journal of Affective Disorders, 93, 213-218. doi: 10.1016/j.jad.2006.01.015

Butters, J. E., Mann, R. E., \& Smart, R. G. (2006). Assessing road rage victimization and perpetration in the Ontario adult population. Canadian Journal of Public Health, 97, 9699. 
Buttiglieri, M. W., \& Guennette, M. (1967a). Driving record of neuropsychiatric patients. Journal of Applied Psychology, 51, 96-100.

Buttiglieri, M. W., \& Guennette, M. (1967b). Temporal relationship between automobile accidents and psychiatric hospitalization. Perceptual and Motor Skills, 24, 1327-1332.

Buttiglieri, M. W., Guennette, M., \& Thomson, M. (1969). Driving record of medical and surgical patients. Perceptual and Motor Skills, 29, 427-434.

Canadian Medical Association. (2006). Determining medical fitness to operate motor vehicles: CMA driver's guide (7 $7^{\text {th }}$ edition). Retrieved from www.cma.ca

Carter, T. (2006). Fitness to drive: A guide for health professionals. London, England: The Royal Society of Medicine Press Ltd.

Carver, C. S., Johnson, S. L., \& Joormann, J. (2008). Serotonergic function, two-mode models of self-regulation, and vulnerability to depression: What depression has in common with impulsive aggression. Psychological Bulletin, 134, 912-943. doi: 10.1037/a0013740

Charlton, J., Koppel, S., O’Hare, M., Andrea, D., Smith, G., Khodr, B., ...Fildes, B. (2004, April). Influence of chronic illness on crash involvement of motor vehicle drivers. Retrieved from http://www.monash.edu.au/muarc/reports/muarc213.pdf

Cross, J. M., McGwin, G., Jr., Rubin, G. S., Ball, K. K., West, S. K., Roenker, D. L., Owsley, C. (2009). Visual and medical risk factors for motor vehicle collision involvement among older drivers. British Journal of Ophthalmology, 93, 400-404. doi: 10.1136/bjo.2008.144584

Cushman, L. A., Good, R. G., \& States, J. D. (1990). Psychiatric disorders and motor vehicle accidents. Psychological Reports, 67, 483-489. 
Dassanayake, T., Michie, P., Carter, G., \& Jones, A. (2011). Effects of benzodiazepines, antidepressants and opioids on driving: a systematic review and meta-analysis of epidemiological and experimental evidence. Drug Safety, 34, 125-156. doi:

$10.2165 / 11539050-000000000-00000$

De Las Cuevas, C., \& Sanz, E. J. (2008). Fitness to drive of psychiatric patients. The Primary Care Companion to the Journal of Clinical Psychiatry, 10, 384-390.

De Las Cuevas, C., \& Sanz, E. J. (2009). Mental illness and road safety. Actas Españolas de Psiquiatría, 37, 75-81.

De las Cuevas, C., Ramallo, Y., \& Sanz, E. J. (2010). Psychomotor performance and fitness to drive: The influence of psychiatric disease and its pharmacological treatment. Psychiatry Research, 176, 236-241. doi:10.1016/j.psychres.2009.02.013

de Winter, J. C. F., de Groot, S., Mulder, M., Wieringa, P. A., Dankelman, J., \& Mulder, M. A. (2009). Relationships between driving simulator performance and driving test results. Ergonomics, 52, 137-153. doi: 10.1080/00140130802277521

Deery, H. A., \& Fildes, B. N. (1999). Young novice driver subtypes: Relationship to high-risk behavior, traffic accident record, and simulator driving performance. Human Factors, 41, 628-643.

Dobbs, B. (2005). Medical conditions and driving: A review of the literature (1960-2000). National Highway Traffic Safety Administration. Downloaded from http://www.nhtsa.gov/people/injury/research/medical_condition_driving/Medical\%20Co nd\%20809\%20690-8-04_Medical\%20Cond\%20809\%20690-8-04.pdf 
Dumais, A., Lesage, A. D., Boyer, R., Lalovic A., Chawky, N., Ménard-Buteau, C., ... Turecki, G. (2005). Psychiatric risk factors for motor vehicle fatalities in young men. Canadian Journal of Psychiatry, 50, 838-844.

Fong, G., Frost, D., \& Stansfeld, S. (2001). Road rage: a psychiatric phenomenon? Social Psychiatry and Psychiatric Epidemiology, 36, 277-86.

Galovski, T. E., Malta, L. S., \& Blanchard, E. B. (2006). Road rage: Assessment and treatment of the angry, aggressive driver. Washington, DC: American Psychological Association. Hammar, A., Lund, A., \& Hugdahl, K. (2003). Selective impairment in effortful information processing in major depression. Journal of the International Neuropsychological Society, 9, 954-959. doi: 10.10170S1355617703960152

Hernetkoski, K. M., Keskinen, E. O., \& Parkkari, I. K. (2009). Driver suicides in Finland - Are they different in northern and southern Finland? International Journal of Circumpolar Health, 68, 249-260.

Hilton, M. F., Staddon, Z., Sheridan, J., \& Whiteford, H. A. (2009). The impact of mental health symptoms on heavy goods vehicle drivers' performance. Accident Analysis and Prevention, 41, 453-461. doi: 10.1016/j.aap.2009.01.012

Hollister, L. E. (1992). Automobile driving by psychiatric patients [Letter to the editor]. The American Journal of Psychiatry, 149, 274.

Holt, P. L. (1981). Stressful life events preceding road traffic accidents. Injury, 13, 111-115.

Isherwood, J., Adam, K. S., \& Hornblow, A. R. (1982). Life event stress, psychosocial factors, suicide attempt and auto-accident proclivity. Journal of Psychosomatic Research, 26, 371-383. 
Keskinen, E., \& Pasanen, A. (1990). Self-destruction in motor vehicle accidents: the proportion of suicides and negligent drivers in fatal motr vehicle accidents in 1974-75 and 1984-85 in Finland. Journal of Traffic Medicine, 18(4), 179-185.

Koepsell, T. D., Wolf, M. E., McCloskey, L., Buchner, D. M., Louie, D., Wagner, E. H., \& Thompson, R. S. (1994). Medical conditions and motor vehicle collision injuries in older adults. Journal of the American Geriatrics Society, 42, 695-700.

Kuroda, N., \& Pounder, D. J. (1994). Suicide on the roads. Journal of Traffic Medicine, 23, 6770.

Linnoila, M., \& Seppala, T. (1985). Antidepressants and driving. Accident Analysis and Prevention, 17, 297-301.

Malta, L. S., Blanchard, E. B., \& Freidenberg, B. M. (2005). Psychiatric and behavioral problems in aggressive drivers. Behaviour Research and Therapy, 43, 1467-1484. doi: 10.1016/j.brat.2004.11.004

Mann, R. E., Asbridge, M., Stoduto, G., Smart, R., G., Goldbloom, D. S., Vingilis, E. R., \& Wickens, C. M. (2010). Psychological distress and collision involvement among adult drivers. Stress and Health, 26, 127-134. doi: 10.1002/smi.1274

Mann, R. E., Cheung, J. T. W., Ialomiteanu, A., Stoduto, G., Chan, V., Wickens, C. M., ... Rehm, J. (2011). Estimating prevalence of anxiety and mood disorder in survey data using the GHQ12: Exploration of threshold values. European Journal of Psychiatry, 25(2), 81-91.

Margolis, K. L., Kerani, R. P., McGovern, P., Songer, T., Cauley, J. A., \& Ensrud, K. E. (2002). Risk factors for motor vehicle crashes in older women. Journal of Gerontology, 57A, M186-M191. 
Marottoli, R. A., Cooney, L. M., Wagner, D. R., Doucette, J., \& Tinetti, M. E. (1994). Predictors of automobile crashes and moving violations among elderly drivers. Annals of Internal Medicine, 121, 842-846.

Marshall, S. C. (2008). The role of reduced fitness to drive due to medical impairments in explaining crashes involving older drivers. Traffic Injury Prevention, 9, 291-298. doi: $10.1080 / 15389580801895244$

Martiniuk, A. L. C., Ivers, R. Q., Glozier, N., Patton, G. C., Senserrick, T., Boufous, S., ... Norton, R. (2010). Does psychological distress increase the risk for motor vehicle crashes in young people? Findings from the DRIVE study. Journal of Adolescent Health, 47, 488-495. doi: 10.1016/j.jadohealth.2010.03.010

Mykletun, A., Bjerkeset, O., Dewey, M., Prince, M., Overland, S., \& Stewart, R. (2007). Anxiety, depression, and cause-specific mortality: The HUNT study. Psychosomatic Medicine, 69, 323-331. doi: 10.1097/PSY.0b013e31803cb862

NZ Transport Agency. (2009). Medical aspects of fitness to drive: A guide for medical practitioners. Retrieved from http://www.nzta.govt.nz/resources/medicalaspects/docs/medical-aspects.pdf

Osterman, R. L., Ribak, J., Bohn, C. M., Fargo, J. D., \& Sommers, M. S. (2009). Screening for hazardous/harmful drinking and depressive symptoms in an at-risk emergency department population. Journal of Addictions Nursing, 20, 34-40. doi: $10.1080 / 10884600802693348$

Rainio, J., Sulander, P., Hantula, L., Nuutinen, J., \& Karkola, K. (2007). Diseases and motor vehicle fatalities in Finland in 2001 and 2002. Traffic Injury Prevention, 8, 321-328. doi: $10.1080 / 15389580601118862$ 
Ramaekers, R. G. (2003). Antidepressants and driver impairment: Empirical evidence from a standard on-the-road-test. Journal of Clinical Psychiatry, 64, 20-29.

Road rage: Causes and dangers of aggressive driving: Hearing before the Subcommittee on Surface Transportation of the Committee on Transportation and Infrastructure, House of Representatives, $105^{\text {th }}$ Cong., 1 (1997).

Sabbe, B., Hulstijn, W., van Hoof, J., Tuynman-Quea, H.G., \& Zitman, F., (1999). Retardation in depression: assessment by means of simple motor tasks. Journal of Affective Disorders, $55,39-44$.

Sagberg, F. (2006). Driver health and crash involvement: A case-control study. Accident Analysis and Prevention, 38, 28-34. doi: 10.1016/j.aap.2005.06.018

Scott-Parker, B., Watson, B., King, M. J., \& Hyde, M. K. (2011). The psychological distress of the young driver: a brief report. Injury Prevention, 17, 275-277. doi: 10.1136/ip.2010.031328

Selzer, M. L., Rogers, J. E., \& Kern, S. (1968). Fatal accidents: The role of psychopathology, social stress, and acute disturbance. American Journal of Psychiatry, 124, 1028-1036.

Selzer, M. L., \& Vinokur, A. (1975). Role of life events in accident causation. Mental Health \& Society, 2, 36-54.

Sims, R. V., McGwin, G., Jr., Allman, R. M., Ball, K., \& Owsley, C. (2000). Exploratory study of incident vehicle crashes among older drivers. Journal of Gerontology, 55A, M22-M27.

Vaa, T. (2003). Impairment, diseases, age and their relative risks of accident involvement: Results from meta-analysis, TØI Report 690 for the Institute of Transport Economics, Oslo, Norway. Retrieved from 
http://www.toi.no/getfile.php/Publikasjoner/T\%D8I\%20rapporter/2003/690-2003/6902003-el.pdf

Vassallo, S., Smart, D., Sanson, A., Cockfield, S., Harris, A., McIntyre, A., \& Harrison, W. (2008). Risky driving among young Australian drivers II: Co-occurrence with other problem behaviours. Accident Analysis and Prevention, 40, 376-386. doi:

10.1016/j.aap.2007.07.004

Vaughn, M. G., Define, R. S., DeLisi, M., Perron, B. E., Beaver, K. M., Fu, Q., \& Howard, M. O. (2011). Sociodemographic, behavioral, and substance use correlates of reckless driving in the United States: Findings from a national sample. Journal of Psychiatric Research, 45, 347-353. doi: 10.1016/j.jpsychires.2010.06.016

Verster, J. C, \& Roth, T. (2012). Predicting psychopharmacological drug effects on actual driving performance (SDLP) from psychometric tests measuring driving-related skills. Psychopharmacology, 220, 293-301. doi: 10.1007/s00213-011-2484-0

Vingilis, E., \& Wilk, P. (2007). Predictors of motor vehicle collision injuries among a nationally representative sample of Canadians. Traffic Injury Prevention, 8, 411-418. doi:

$10.1080 / 15389580701626202$

Vingilis, E., \& Wilk, P. (2012). Medical conditions, medical use, and their relationship with subsequent motor vehicle injuries: Examination of the Canadian National Population Health Survey. Traffic Injury Prevention, 13, 327-336. doi:

$10.1080 / 15389588.2012 .654411$

Waller, J. A. (1965). Chronic medical conditions and traffic safety: Review of the California experience. The New England Journal of Medicine, 273(26), 1413-1420. 
Wickens, C. M., Mann, R. E., Butters, J., Smart, R. G., \& Stoduto, G. (2014). Road Rage. In B. Puri \& I. Treasaden (Eds.), Forensic psychiatry. Hodder Arnold (in press).

Wickens, C. M., Mann, R. E., Stoduto, G., Ialomiteanu, A., Smart, R. G., \& Rehm, J. (2013). The impact of probable anxiety and mood disorder on self-reported collisions. Journal of Affective Disorders, 145, 253-255. doi: 10.1016/j.jad.2012.04.046

Wingen, M., Ramaekers, J. G., \& Schmitt, J. A. J. (2006). Driving impairment in depressed patients receiving long-term antidepressant treatment. Psychopharmacology, 188, 84-91.

World Health Organization. (2009). Global status report on road safety: Time for action. Retrieved from http://whqlibdoc.who.int/publications/2009/9789241563840_eng.pdf

Wulsin, L., Vaillant, G. E., \& Wells, V. E. (1999). A systematic review of the mortality of depression. Psychosomatic Medicine, 61, 6-17.

Wyman, L., Crum, R. M., \& Celentano, D. (2012). Depressed mood and cause-specific mortality: A 40-year general community assessment. Annals of Epidemiology, 22, 638643. doi: /10.1016/j.annepidem.2012.06.102

Yu, J., Evans, P. C., \& Perfetti, L. (2004). Road aggression among drinking drivers: Alcohol and non-alcohol effects on aggressive driving and road rage. Journal of Criminal Justice, 32, 421-430. doi: 10.1016/j.jcrimjus.2004.06.004 